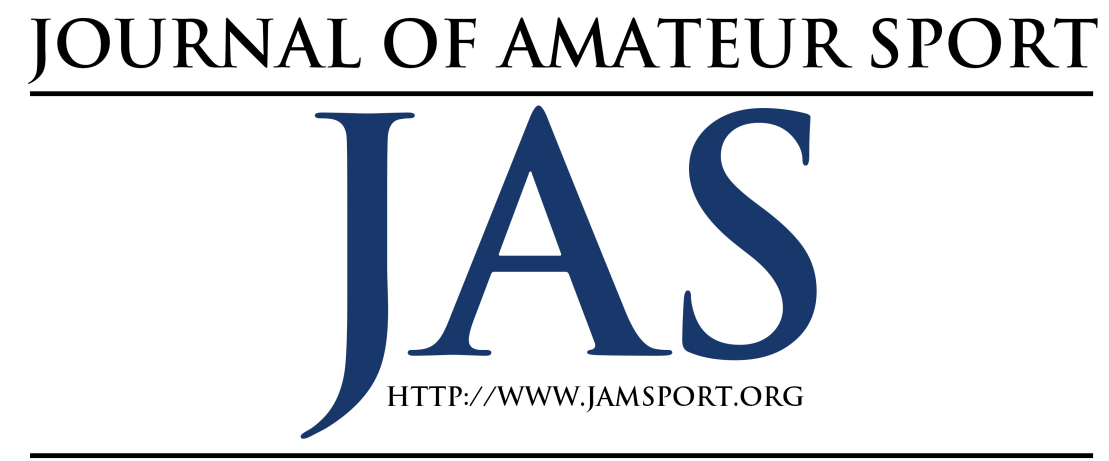

\title{
Social Geographies at Play: Mapping the Spatial Politics of Community-Based Youth Sport Participation
}

\author{
Amy Chan Hyung $\mathrm{Kim}^{1}$ \\ Christopher Coutts ${ }^{1}$ \\ Joshua I. Newman ${ }^{1}$ \\ Simon Brandon-Lai ${ }^{1}$ \\ Minjung $\mathrm{Kim}^{2}$ \\ ${ }^{1}$ Florida State University \\ ${ }^{2}$ East Stroudsburg University
}

\begin{abstract}
Organized youth sports programs (YSP) provide opportunities for participation in physical activity, and represent an important part of the broader public health agenda in the United States. YSP not only provide physiological health benefits through active participation, but also promote social relationships within communities. In this study, we (1) investigated participants' travel to access YSP located in neighborhoods historically delineated by an over/under-representation of socio-economic and/or racial homogeneity; and (2) examined the neighborhood demographics for those YSP participants who traveled the most/least to participate. To do this, we analyzed five years of demographic and geographic information system (GIS) visualization data from participants in a publically-provisioned youth sport league network. We found significant differences between the travel distances of participants in different sports, and between the travel distances of participants from neighborhoods with different racial and/or socio-economic composition. This research expands understanding of the potential segregation effects of community-based YSP for various stakeholder groups.
\end{abstract}

$\mathrm{I}$ n sport settings, community-based youth sport programming - such as organized baseball, football, basketball, volleyball, and soccer- has been posited as an effective "intervention" to enhance public health and physical activity among participating children (e.g., Small, 2002) and promote social relationships among community members (e.g., Houlihan \& Green, 2008). According to the National 
Council of Youth Sports (NCYS) roughly 60 million youth are currently registered to participate in organized youth sport programs across the United States (NCYS, 2015). The expansion of publicly provisioned forms of structured, extracurricular (non-school sanctioned) physical activity has been a defining feature of the broader national public health agenda since the latter part of the $19^{\text {th }}$ Century (Eitzen \& Sage, 2009). Local parks and recreation departments, community centers, nongovernmental organizations, and grassroots sport programs have for over a century been charged with maximizing access to, and participation in, these non-elite forms of amateur athletics.

With concern for maximizing the benefits of participating in youth sport programs (YSP), scholars from fields such as education, public health, epidemiology, sociology, and sport management have for decades examined the positive effects of community-level sport initiatives and programs (e.g., Dishman, Heath, \& Lee, 2013; Finch \& Donaldson, 2010; Hill, 1965; Maxwell \& Taylor, 2010; Schulenkorf \& Edwards, 2012) and correlates of participating in YSP and positive health outcomes (e.g., Biddle, Mutrie, \& Gorely, 2015; Kahn, Thompson, Blair, Sallis, Powell, Bull, \& Baumann, 2012; Mandic, Bengoechea, Stevens, de la Barra, \& Skidmore, 2012; van der Horst, Paw, Twisk, \& Van Mechelen, 2007). Likewise, public policymakers, administrators, and urban and regional planners across the country (and around the world) have endeavored to build sport-specific programming and infrastructure (community centers, parks, field, etc.) to accommodate the needs of a given population (city, county, region, state) by reducing barriers to access (Downward \& Rasciute, 2010; Wicker, Hallmann, \& Breuer, 2013; Xiong, 2007). This has resulted in what has become a popular "community-based" approach to delivering structured sport programming (namely youth sport activities); an approach premised on the idea that to optimize public sport provision in a given area, administrators should strategically locate sport facilities and activities in locations that would present the fewest proximity (to homes, schools, neighborhoods) barriers and engender the greatest sense of participatory stakeholdership (Strong, Malina, Blimkie, Daniels, Dishman, Gutin, \& Rowland, 2005).

Research has illustrated that in many contexts, a community-based approach to youth sport programming has led to both positive health outcomes and increased social cohesion (Eime \& Payne, 2009; Roux, Pratt, Tengs, Yore, Yanagawa, van Den Bos, Rutt, Brownson, Powell, Heath, Kohl III, Teutsch, Cawley, Lee, West, \& Buchner, 2008). Practitioners have developed new programs - often at new facilities - that resulted in increased participation and enhanced geospatially-defined communities (i.e. intra-neighborhood communities). New sport programs have galvanized interneighborhood communities, bringing 
together kids from varying socio-economic backgrounds and neighborhoods to forge a new sport-specific community. This has led to the emergence and strengthening of spatially-defined (often demographically homogenous) communities through sport (i.e. Baltimore's Roland Park lacrosse community). In addition, youth sport as acted as a catalyst for the constitution of new inter-neighborhood sport-based communities (i.e. the Shelby County youth soccer leagues).

This community-based approach, both in scholarship and in practice, brings into question premises and broad conceptions of "community." In some instances, "community" refers to citizens or members of a particular geo-spatial area (i.e. residents within a neighborhood, a town or city, or a county or region). In other instances, "community" refers to a group bound together by a shared ethnic, national, or cultural heritage and practices (i.e. "the African-American Community," "the Korean diaspora," or "the Jewish community"). Further still, the term "community" is sometimes used in local sport contexts to refer to established social networks formed around specific sport organizations or subcultures (i.e. "the North suburbs soccer community," "the skating community," etc.). This unfixed meaning is more than a matter simple linguistic ambiguity. Understanding how certain sports activities, in particular geo-spatial arrangements, are positioned to produce or strengthen "community" ties within and across these differential and potentially competing definitional configurations is key.

In a physical sense, organized youth sport-particularly when in a team setting - brings people together. Parents and youth in YSP congregate to share in cooperative and competitive social bonding activities. If the sport community is being built around an impetus to strengthen the demographically- and socially-bounded neighborhood, then organized sport could serve as an important platform for strengthening ties amongst geographically and socio-economically associated families. This presents both potentially positive (e.g., stronger sense of community, better ingroup relations, ease of access and thus fewer geo-spatial barriers, etc.) and negative (e.g., homophily effects, re-segregation) outcomes. By contrast, sport communities built around an impetus to bring together stakeholders from across sociodemographic or geographic neighborhoods creates a different series of outcomesincreased inter-neighborhood socialization, diversification of unit (team) sociodemographic plurality, more geo-spatial barriers, and a loosening of neighborhood ties.

In this study, we explore two simple questions: first, who comes together in the community-based youth sport environment, and, second, where do they come from? Correlates of physical activity have tended to be categorized into six essential categories (i.e., socio-demographic correlates, biological correlates, 
psychological correlates, behavioral correlates, socio-cultural correlates, and environmental correlates) (see Biddle et al., 2015, for detailed information). However, there is a paucity of research devoted to understanding the geographic structuration and political spatialization of communitybased youth sport. That is, how the spatial environment structures and potentially influences correlative outcomes. To address this gap, we employ geographic information system (GIS) techniques to examine the relationship between the type of program or activity and socio-demographic neighborhood structuration (of both facility location and the participating family) by tracking specified spatial locations (Seifried, 2011). In this study, we follow Biddle et al.'s (2015) approach by mapping the sociodemographic correlates (e.g., race, age, gender, socio-economic status) and geographic correlates (e.g., facility and program access) of YSP participation. To this end, we render a network-wide (within a county-wide sport league system administered by a central governing body) analysis that maps out: 1) do participants travel outside of their neighborhood to access certain youth sport programs located in neighborhoods historically delineated by an over- or under-representation of socioeconomic and/or racial diversity (and are there differences based on sport-type?), and 2) what are the neighborhood demographics for those YSP participant who travel the most or least to play youth sports? To do this, we provide an analysis of GIS visualization data extracted from five years of youth sport participation in a publicallyprovisioned youth sport league network of a mid-sized city in the Southeastern United States.

This research is critical to expanding our understanding of the segregation effects community-based YSP might create for participating youth, their parents/guardians, and the neighborhoods in which they reside. Given a majority of popular sports such as basketball, baseball, soccer, softball, volleyball, and football are provided within most municipality or county networks (Dixon \& Bruening, 2014), it is important to consider the extent to which the location of YSP practices and games might not only present barriers for those with limited means of transportation (Atkins, Sallis, Saelens, Cain, \& Black, 2005; Owen, Leslie, Salmon, \& Fotheringham, 2000; Owen, Humpel, Leslie, Bauman, \& Sallis, 2004, Wicker et al., 2013), but also re-entrench or break down established patterns of socioeconomic and racial segregation. Although environmental factors such as sociodemographic characteristics and travel distance have been considered significant factors within physical activity literature (Davison \& Lawson, 2006; Gordon-Larsen, Nelson, Page, \& Popkin, 2006), few studies have explored the associations of the facility location and team sport's broader community-building capacities (Balish, McLaren, Rainham, \& Blanchard, 2014). Ultimately, the present study provides critical insights for sport administrators to 
make more informed decisions about site location, programming, and access points to places of play. This can be beneficial in developing socially and geographically heterogeneous (and heterogenizing) practices for encouraging participation in YSPs.

\section{Review of Literature} Youth Sport Participation: Outcomes and Correlates

Sport is an effective and powerful tool to promote health and well-being for youth (Holt, 2008). Despite potential negative outcomes such as injuries (Khan et al., 2012) or hazing (Crow \& Macintosh, 2009; Edelman, 2004; Rosner \& Crow, 2002), most scholars agree that the positive outcomes surpass these negative effects, and have specifically highlighted the effectiveness of promoting physical activity (Alfano, Kleges, Murray, Beech, \& McClananhan, 2002; Barber, Eccles, \& Stone, 2001; Eccles, Barber, Stone, \& Hunt, 2003; Larson, 2000; Mahoney, Larson, \&

Eccles, 2005; Peretti-Watel et al., 2003;

Perkins, Jacobs, Barber, \& Eccles, 2004). In addition, previous research indicates positive outcomes can also include: 1) positive youth development (Barber et al., 2001; Eccles, Barber, Stone, \& Hunt, 2003; Larson, 2000; Mahoney et al., 2005; PerettiWatel et al., 2003), 2) learning skills to develop identity and emotion (Hansen, Larson, \& Dworkin, 2003), 3) increased academic achievement (Marsh \& Kleitman, 2003), 4) increased levels of intrinsic motivation and concentration (Lowe Vandell, Shernoff, Pierce, Bolt, Dadisman, \& Brown, 2005), 5) decreased likelihood of risky behavior such as smoking (AudrainMcGovern, Rodriquez, Wileyto, Schmitz, \& Shields, 2006), and 6) decreased depression and suicidal behavior (Brown \& Blanton, 2002; Sabo, Miller, Melnick, Farrell, \& Barnes, 2005). While definitions of youth sport participation and physical activity participation are different, previous studies note that correlates of both sport and physical activity are categorized into similar schema among youth (Balish et al., 2014; Dollman \& Lewis, 2010; Michaud, Jeannin, \& Suris, 2006). Yet compared to reviews of physical activity, only a handful of studies have reviewed the role of youth sport participation. The present study focuses specifically on socio-demographic correlates and environmental correlates (Sallis, Prochaska, \& Taylor, 2000).

A series of studies have identified age and gender as the most important correlates of physical activity participation (e.g., Alfano et al., 2002; Audrain-BcGovern et al., 2006; Balish et al., 2014). To be specific, males have reported more physical activity than females, while children have reported more physical activity than adolescents (Biddle et al., 2015). In addition, studies on ethnicity have disclosed that White individuals have more physical activity than other groups. Such results varied depending on geographic location (i.e., different countries, different regions within one country) (Biddle et al., 2015). 
According to Stalsberg and Pedersen (2010), 37 out of 60 studies involving socioeconomic status (SES) confirmed a positive relationship between SES and physical activity, whereas 20 found no significant relationship, and only 6 detected a negative relationship. In addition, significant environmental correlates include travel distance/facility access (Ferreira et al., 2007; Sallis et al., 2000), outdoor activity (Hinkley, Crawford, Salmon, Okely, \& Hesketh, 2008), and crime rate (Davison \& Lawson, 2006). The present study investigates two vital correlates, sociodemographic and environmental, to study YSP participation.

\section{A Cultural Geography of Play: Socio- Demographic Characteristics, Sport} Types, and Travel Distances in YSP

Parents play a critical role in determining what kind of sports their children participate in and what resources they employ to access those activities (Welk, Wood, \& Morss, 2003). To be specific, studies have confirmed that these decisions can be affected by SES (Gottlieb \& Chen, 1985; Sallis, Alcaraz, McKenzie, Hovell, Kolody, \& Nader, 1992; Sallis, Nader, Broyles, Berry, Elder, McKenzie, \& Nelson, 1993; Yang, Telama, \& Laakso, 1996) and race (Bungum \& Vincent, 1997; Garcia, Broda, Frenn, Coviak, Pender, \& Ronis, 1995). Specifically, previous research suggests SES has a positive relationship with the rate of sport participation (Gottlieb \& Chen, 1985; Sallis et al., 1992; Sallis et al.,
1993; Yang, Telama, \& Laakso, 1996). The same tendencies have been observed among youth sport participants. For children in socially- and economically disadvantaged neighborhoods, three patterns have been identified: 1) children from neighborhoods with high SES profiles are more likely to be involved in sports, 2) children from lower SES groupings are more inclined to engage in contact sports such as football, and 3) children from socially- and economically disadvantaged neighborhoods tend to participate in sports that demand little equipment or that are publicly funded programs (The Aspen Institute, 2015).

In the present study we analyzed the distance parents with varied sociodemographic profiles (i.e., race, income) travel to access YSP. We also examined the extent that sport types (e.g., volleyball, soccer, football, etc.) mediate willingness to travel farther and/or to play in neighborhoods with similar or different SES profiles. On the surface, this interrelationship between geographic (travel, neighborhoods), socio-demographic (race, income), and sport participation factors might not seem of critical concern to the political economy of sport and physical activity. However, as we will make clear in what follows, it is those inter-relationships between sporting bodies and space-and the distribution and movement of populations therein - that constitute the paradoxical inter- and intra-neighborhood capacity for sport-based communitybuilding. Indeed, the social and physical 
health outcomes of community-based youth sport participation are largely contingent on the location where the activity takes place, the production function the sport-specific human movement has played and continues to play in segregating fields of social interactivity, and the extent to which social participants locate themselves in and amongst spatially- or socially-anchored members of the broader population. As such, we argue that community-based sport operates at the confluence of what W. E. B. DuBois would have referred to as two traditionally "segregationalizing" politicalgeographic institutions: the neighborhood and sport.

\section{Residential Segregation}

The population health and cultural geography scholar Douglas Massey describes residential segregation as "the degree to which two or more groups live separately from one another, in different parts of the urban environment" (Massey \& Denton, 1988a, p, 282). In a series of widely cited studies of the urban United States in the 1980s, Massey and his colleagues (Denton \& Massey, 1988; Massey, 1985; Massey \& Denton, 1988a; 1988b) explicate the historical and political determinants of inter-neighborhood segregation practices. They point to a series of associations that concurrently contribute to reproducing segregated neighborhood and housing practices:

Minority members may be distributed so that they are overrepresented in some areas and underrepresented in others, varying on the characteristic of evenness. They may be distributed so that their exposure to majority members is limited by virtue of rarely sharing a neighborhood with them. They may be spatially concentrated within a very small area, occupying less physical space than majority members. They may be spatially centralized, congregating around the urban core, and occupying a more central location than the majority. Finally, areas of minority settlement may be tightly clustered to form one large contiguous enclave, or be scattered widely around the urban area. (Massey \& Denton, 1988a, p. 283)

At its core, their analysis points to the extent to which social (discrimination, socialization, etc.) and political (public policy, housing, urban and regional planning, etc.) practices lead to the reproduction of racial and socio-economic groupings across the urban terrain. They also illustrate the extent to which public infrastructural and institutional works often contribute to further clustering where people live, who has access to public facilities, where groups interact, and how they valorize the benefits of public works.

For our purposes, the concept of residential segregation provides a useful hermeneutic device for exploring the extent to which publicly provided sport-when administered at numerous and scattered sites across the city geography — can serve to reconstitute (based on location, access, or 
activities undertaken on site) or eliminate longstanding residential segregation practices. Indeed, given that youth sports tend to bring people together to interact in a group environment (as member of the team, as one of many spectators) and at a central location, who goes where, and interacts with whom, could hold potential for integrating members of disparate neighborhoods through practices of common interest. Conversely, if the membership of a given team or league at a specific site is considerably over-represented by participants from the same racially- or socially-homogenous neighborhood-at a location within that neighborhood-it could serve the double function of reinforcing segregative practices (negative) and strengthening community ties (positive).

\section{Sport Segregation}

In the United States, as elsewhere, wide disparities and inequalities in economic resources among different social classes have influenced both access to and social discrimination within sport participation. The research has consistently shown that both adults and youth from high-income, high-education, and high-status occupational groups engage in greater rates and levels of sport participation. A survey across all types of individual and team sport activities (e.g., football, basketball, baseball, volleyball, soccer, softball, golf, tennis, swimming, sailing) reveals strong patterns of association between income and rates of sport participation (Eitzen \& Sage, 2009).
Notably, greater disparities continue to persist in sports that require special access to private clubs or facilities such as golf, tennis, and skiing (Eitzen \& Sage, 2009). Similarly, patterns of racial segregation continue to exist in sport in the United States. African-Americans have been found to participate disproportionately in some sports due to the 'sports opportunity structure' (Frey \& Eitzen, 1991). When it comes to sport types, African-Americans are generally under-represented in sports that demand facilities and coaching often held in expensive and exclusive clubs (Frey \& Eitzen, 1991). As such, scholars have surmised that while sport is no longer formally segregated by race-based participation limitations, many sport leagues and teams in various cities continue to act as informal segregating institutions. As Glover (2007) explicates, racism can exist even within YSPs that institute "color-blind" policies. Indeed, sports such as soccer and baseball tend to be more popular in most cities over-represented by higher SES and White participants (relative to the city's overall demographic profile), and sports such as football and basketball continue to be over-represented by low SES and minority racial groups (Glover, 2007).

Figure 1 serves as a loose framework for explaining the segregating effects of home neighborhood location (neighborhood demographics, starting point for travel distance to access sport facilities, etc.) on the community-building capacities and outcomes of YSP. In this study, we utilized 
demographic data and geospatial coding to create statistical and visualization based analysis of these complex interrelationships. We then illustrate the extent to which-within the designated community-based youth sport networkspecific configurations of sport type and facility location: 1) bring together participants from close proximities (while others draw in participants from across the city) and 2) attract participants from neighborhoods with varied SES and racial profiles.

\section{Methods}

\section{Data Collection}

The researchers retrieved archival data of registration information between 2010 and 2014 from the Parks, Recreation, and Neighborhood Affairs Department of a mid-sized (metro population between 250,000 and 500,000 ) city in the Southeastern United States. Each year, this municipality's Parks, Recreation, and Neighborhood Affairs Department administers eight different types of sport programs (i.e., tackle football, flag football, volleyball, cheerleading, soccer, basketball, baseball/t-ball, and softball) across three seasons (i.e., fall, winter, spring). Worth noting here, all participating families are free to choose which facility to practice and play home matches/games. As such, there is no artificial administrative mechanism that mediates the relationship between home location and choice of sport facility location (i.e. they do not have to play in a certain district or zone based on home address). The information of 6,021 households was collected for a cross-platform GIS and sport typology analysis. Demographic data were acquired at the census block group level using the 2011 American Community Survey 5-year average. Race, median income, and employment status data describing the 235 census block groups in which the subjects lived were attributed to each observation. The 2011 GIS census block group TIGER/Line ${ }^{\circledR}$ shapefiles were retrieved from the US Census Bureau.

\section{Data Analysis}

The research team employed ArcGIS v10.1 to geo-code the observations in order to determine the distances children travelled to a facility to participate in their YSP. The road network reference dataset was the Florida Department of Transportation Base Map, an extremely robust dataset that is updated quarterly. The address locator was built within the ArcGIS desktop application. A total of 272 observations were discarded before the geocoding procedure due to nonresponse or if they provided a P.O. Box as an address. This left a total of 5,749 observations. The match rate for geocoding was exceptional, varying by sport within the range of $97.3 \%$ and $100 \%$ at an average of $98.41 \%$. 90 observations could not be geocoded and were dropped, and a further seven were lost due to them being incorrectly geo-located. This left a total of 5,652 observations for the analysis. The municipality's 19 sport and recreation 
facilities were also geocoded using the same reference dataset and address locator. The 5,652 children were then paired with the facility at which they participate in YSP. The distance between a child's home and facility was calculated using a road network distance. This is considered an improvement over an as-the-crow-flies (Euclidian) distance as it represents actual travel distances.

We employed a series of statistical analysis using StataSE v12.1. A one-way ANOVA procedure was used to examine whether there was a significant difference among eight different sport types in the mean distance travelled to their respective facilities. We then conducted a univariate regression analysis with miles travelled as the dependent variable and the percent white of the neighborhood in which the participant lives as the independent variable. A test of mean significance ( $t$-test) was used to examine if there was significant difference between female-only sports (i.e., volleyball, cheerleading, and softball) and other co-ed or male sports (i.e., tackle football, flag football, soccer, basketball, baseball/t-ball).

A Gettis-Ord Gi* statistic was calculated using ArcGIS v10.1 for the variable of distance travelled to facilities. The $\mathrm{Gi}^{*}$ statistic identifies statistically significant "hot spots" and "cold spots" of spatial clustering. For statistically significant clustering to occur, a feature with a high or low value will be found in close proximity to features with similarly high or low values.
The results of the statistic are $z$-score values that are interpreted as standard deviations. Values over 1.96 or under -1.96 are statistically significant at the $p<0.05$ level. Values over 2.58 or below -2.58 are statistically significant at the $p<0.01$ level. This statistic provides a quantitative assessment to illuminate those parts of the metro region where participants of YSP travelling above and below the mean distances to reach facilities spatially cluster. Fixed distance was the conceptualized spatial relationship for the $\mathrm{Gi}^{*}$ test, and the default fixed distance was used. The default fixed distance uses the minimum distance that ensures every observation has at least one neighbor for the analysis.

\section{Results}

Table 1 displays the number of participants by facility and sport. As table 1 indicates, in general, facilities with more sports had more participants . Conversely, there was no relationship between the number of participants of a given sport and the number of facilities at which that sport is played. With respect to average distance travelled, participants who played volleyball and softball travelled farther than other sports. The mean number of miles travelled for entire sample was 4.8, ranging from 0.12 to 32.6 miles.

As shown in Table 2, the one-way ANOVA procedure revealed that there was a significant difference among eight different types of sport in the mean distance traveled to their assigned facilities $(p<0.01)$. 
The sports that deviated the most from the mean travel distance for all sports $(\mu=4.8$ miles) were volleyball ( $\mu=6.8$ miles) and softball ( $\mu=5.9$ miles). This may be due to the fact that all volleyball participants played at one facility. Similarly, there were only four different softball facility locations, second only to volleyball in terms of fewest number of facilities. Also, it is interesting to note that only $0.008 \%$ of the sample lived within walking distance ( 0.25 miles) of the facility where they played their chosen sport. Almost all YSP participants are therefore likely to drive, or take some form of limited public transportation, to reach a given facility.

Table 3 and Table 4 present the description of race proportions and median income of sport participants'. In most of the sports, participants were from predominantly White neighborhoods. The blocks comprising of participants of tackle football and cheerleading were racially neutral. The mean percent of White and African-American participants was derived from a pool of neighborhood values that ranged from 0 to 100 percent. As a whole, a total of 2,055 participants came from the neighborhoods that were above the mean percent of African-Americans (25\%) for neighborhoods in the metropolitan region. Also, aside from the neighborhoods of participants in tackle football and cheerleading, mean income ranged from $\$ 61,146$ to $\$ 78,323$. Baseball participants' had the highest median income, while participants of tackle football and cheerleading were $\$ 48,866$, and $\$ 47,465$ respectively.

As shown in Table 5, the results of a multivariate regression analysis showed that the travel distance to participate in YSP increases as the percentage of White residents from their home neighborhood (census block group) increases. Specifically, controlling for median income and the number of persons unemployed, for every $1 \%$ increase in the percent white of the neighborhood, the distance they travel to a facility increases by 0.031 miles $(p<0.01)$. Figure 2 represents the relationships between travel distance and the percent of white in neighborhoods.

In this figure, a total of 19 facilities were mapped out with graduated symbols. The larger the symbol, the farther the average YSP participating family travelled to attend events held there. While it might be assumed that locations closer to downtown may have shorter travel distances due to increased residential densities, the result of Figure 2 suggests an alternative pattern. Many of the facilities located in suburban neighborhoods, namely those overrepresented by White residents-drew participants from a wider footprint than those more centrally located and certainly those located in neighborhoods overrepresented with minority residents. With regard to income and facility travel distance, the results of a univariate regression analysis showed that there was no significant relationship between median income of neighborhoods of participants and travel 
distance. The results of the t-test showed that there was a significant difference in miles travelled by participants that are exclusively female $(M=5.9, S D=3.8)$ as compared to all other sports $(M=4.7$, $S D=3.5)$ at .01 level.

Figure 3 reveals the results of a cluster analysis. Red dots represent the participants who traveled greater distances from home to reach a facility at .01 level, while blue dots represent the participants who traveled shorter distances from home to reach a facility at .01 level. Only blue dots and red dots represent statistically significant clusters. The results showed that children that live out of town were more likely to play the sport not played at their local facility.

Figures 4 to 11 are the maps for the cluster analysis by sport. As same as Figure 3 , red dots represent the participants who traveled greater distances from home to reach a facility at .01 level while dark orange dots represent the ones who traveled greater distances from home to reach a facility at .05 level. Blue dots represent the participants who traveled shorter distances from home to reach a facility at .01 level while green dots represent the ones who traveled shorter distance from home to reach a facility at .05 level. The succession of figures reveals that there is significant clustering of youth sport participants living in close proximity to others who travel similarly short and long distances to reach facilities, and that these patterns of significant clustering shift by sport.
The contrast in travel distance clustering is evident when comparing sports such as tackle football (home neighborhoods overrepresented by non-White participants) and flag football (home neighborhoods more consistent with city's overall demographic profile). In tackle football there is no significant clustering, implying that participants that live close to one another vary greatly in the distances they travel to reach facilities. However, it is also clear that participants traveling from neighborhoods over-represented by White residents are willing to travel farther to play the sport than are those participants originating from neighborhoods over-represented by racial minorities. In flag football there is significant clustering of participants traveling longer distances to reach facilities (red) and shorter distances to reach facilities (blue), with those traveling shorter distances clustered on the east side of the city (the location of most of the city's neighborhoods over-resented by White residents). It is also worth noting that a considerable contingent of flag football players from the northeastern corridor of the city (location of many of the city's almost exclusively White neighborhoods) stayed within their neighborhood to play flag football.

\section{Discussion}

Overall, only $0.008 \%$ of the sample lived within walking distance $(<0.25$ miles) of the facility that they participated in YSP at. As such, the majority of participants need to use public transportation or drive a 
private vehicle to the facilities. A series of analyses disclosed the dynamics among travel distance, sport types, and sociodemographic characteristics. First, the results showed that a total of 5,652 participants played at 19 facilities. A total of nine facilities were used by 373 participants from 16 tackle football teams; whereas a total of 11 facilities were used by 1,294 participants from 90 flag football teams and by 1,374 participants from a total of 123 soccer teams. As a general trend, what is revealed by the GIS visualization analysis is that for many sports - namely soccer, flag football, and to a lesser extent baseball and softball—parents from racially homogenous neighborhoods are choosing to travel outside of their home neighborhood to participate at facilities with a heterogeneous racial and SES profile. As such, we might surmise that sport-based "communities" are being forged more around cultural and social activities associated with the sport than with a socio-geographic configuration. Conversely, in sports such as basketball and tackle football, participants are significantly more likely to stay within or close to their home neighborhoods. As such, we might conclude that these sports promote inneighborhood community building — but possibly at the expense of cultural integration/desegregation.

Primarily, sport participation entails two types of resources - opportunities to be involved in sport programs and motivation to go along with those opportunities. As a policy maker and YSP organizer, it is vital to promote both because these two resources are interrelated. In other words, opportunities can affect motivation and motivation can affect opportunities. The study of sport participation has typically emphasized individual factors related to youth's self-selection out of sport, rather than reduced opportunities (i.e., lack of sport leagues) (Balish et al., 2014). The results of this study tease out the significance of increasing more opportunities. Participants of volleyball and softball tended to travel farther than other participants because of the restricted number of facilities. The results of one-way ANOVA procedures confirmed that there was a significant difference in the mean distance travelled to facilities among the different sports. For instance, only one facility served a total of 249 participants from the 21 volleyball teams, and only four facilities served a total of 370 participants for the 37 softball teams. Parents seem to be overcoming this potential barrier so that their child can play a certain girl-only or girldominant sport. In fact, if parents wanted their girls to play this league in the fall season there was no choice but participate in volleyball or softball, because all other sport leagues were male-oriented sports. For girls that want to participate in a more traditional form of sport, their only choice is to participate in volleyball. Similarly, the only option for girls in the spring season is softball or male-oriented baseball leagues. Consequently, further investigation is needed to determine if this restricted 
number of facilities is a barrier to participation in female sports. At the same time, more options may be needed for girls' YSP participation. This could be achieved by offering more co-ed friendly recreational sports such as ultimate frisbee or by encouraging greater female participation in existing co-ed compatible sports such as flag football.

\section{Limitations and Future Implications}

This study used the block data rather than individual data to investigate sociodemographic information. For future studies, it may be important to collect selfreported data of individual participants and compare it with block data. This study used travel distance to reflect the sport infrastructure influence, but other quantitative measurements may have highlighted different components of the spatial environment that also influence participation in YSP. For instance, an urban sprawl index was calculated based on residential density, land use mix, degree of centering and street accessibility (Ewing, Schmid, Killingsworth, Zlot, \& Raudenbush, 2003), which might explain another aspect of environmental factors focusing on infrastructure conditions impacting this study. The sample for this study used the public community-based YSP. However, as many sport sociologists have contended (Eitzen \& Sage, 2009 for more information), the nature of sport programs offered by private country clubs or private sport programs is very different from public programs. In the former type of sport programs, participants have more opportunities to work with a greater number of coaches and play sports at facilities with better equipment. Consequently, it may be important to broaden the scope of samples in future studies.

The role of travel distance in sport participation has been controversial. For instance, Boiché and Sarrazin (2009) claimed that a greater distance may influence the decision to drop out of sport activities. On the contrary, Balish and colleagues (2014) confirmed that sport participants are inclined to travel a greater distance to sport programs than people who discontinued participating in sports. Although this study disclosed the role of travel distance among sport participants related to socio-demographic characteristics and sport types, future studies may need to examine the role of distance with people who dropped out from the sport programs as well.

Moreover, while many studies have borrowed eminent theories such as selfdetermination theory, social cognitive theory, and the theory of planned behavior to explain predictions of sport participation (Balish et al., 2014), these theories have not been successful at illustrating how environmental variables such as facility location and travel distance may be associated with sport participation and dropout of sport programs. Future studies may need to bring a modeled conceptual 
framework with theoretical backgrounds to explain the role of environmental variables within organized sport programs more broadly. The concepts and theories surrounding social segregation, social inclusion, and social exclusion may be helpful. 


\section{References}

Alfano, C. M., Kleges, R. C., Murray, D. M., Beech, B. M., \& McClananhan. (2002). History of sport participation in relation to obesity and related health behaviors in women. Preventative Medicine, 34, 82-89. Atkinson, J. L., Sallis, J. F., Saelens, B. E., Cain, K. L., \& Black, J. B. (2005). The association of neighborhood design and recreational environments with physical activity. American Journal of Health Promotion, 19, 304-309.

Audrain-McGovern, J., Rodriquez, D., Wileyto, P., Schmitz, K. H., \& Shields, P. G. (2006). Effect of team sport participation in genetic predisposition to adolescent smoking progression. Archives of General Psychiatry, 63, 433-441.

Balish, S. M., McLaren, C., Rainham, D., \& Blanchard, C. (2014). Correlates of youth sport attrition: A review and future directions. Psychology of Sport and Exercise, 15, 429-439.

Barber, B. L., Eccles, J. S., \& Stone, M. R. (2001). Whatever happened to the Jock, the Brain, and the Princess? Young adult pathways linked to adolescent activity involvement and social identity. Journal of Adolescent Research, 16, 429-455.

Biddle, S., Mutrie, N., \& Gorely, T. (2015). Psychology of physical activity:

Determinants, well-being and intervention (3rd ed.). New York, NY: Routledge.
Boiché, J., \& Sarrazin, P. (2009). Proximal and distal factors associated with dropout versus maintained participation in organized sport. Journal of Sports Science and Medicine, 8, 9-16.

Brown, D. R., \& Blanton, C. J. (2002). Physical activity, sport participation, and suicidal behavior among college students. Medicine and Science in Sports and Exercise, 34, 1087-1096.

Bungum, T. J., \& Vincent, M. L. (1997). Determinants of physical activity among female adolescents. American Journal of Preventive Medicine, 13(2), 115-122.

Crow, R. B., \& Macintosh, E. W. (2009). Conceptualizing a meaningful definition of hazing in sport. European Sport Management Quarterly, 9(4), 433451.

Davison, K. K., \& Lawson, C. T. (2006). Do attributes in the physical environment influence children's physical activity? A review of the literature. International Journal of Behavioral Nutrition and Physical Activity, 3, 19.

Denton, N. A., \& Massey, D. S. (1988). Residential segregation of blacks, Hispanics, and Asians by socioeconomic status and generation. Social Science Quarterly, 69(4), 797-817.

Dishman, R. K., Heath, G. W., \& Lee, I.-M. (2013). Physical activity epidemiology (2nd ed.). Champaign, IL: Human Kinetics. 
Dixon, M., \& Bruening, J. (2014). Community and youth sport. In P. M. Pedersen \& L. Thibault (Eds.), Contemporary sport management (5th ed., pp. 140-160). Champaign, IL: Human Kinetics.

Dollman, J., \& Lewis, N. R. (2010). The impact of socioeconomic position on sport participation among South Australian youth. Journal of Science and Medicine in Sport, 13(3), 318-322.

Downward, P., \& Rasciute, S. (2010). The relative demands for sports and leisure in England. European Sport Management Quarterly, 10, 189-214.

Eccles, J. S., Barber, B. L., Stone, M. R., \& Hunt, J. (2003). Extracurricular activities and adolescent development. Journal of Social Issues, 59(865-889).

Edelman, M. (2004). Addressing the high school hazing problem: Why lawmakers need to impose a duty to act on schools. Pace Law Review, 25(1), 15-47.

Eime, R. M., \& Payne, W. R. (2009). Linking participants in school-based sport programs to community clubs. Journal of Science and Medicine in Sport, 12(2), 293-299.

Eitzen, S., \& Sage, G. (2009). Sociology of North American Sport (8th ed.). Boulder, CO: Paradigm Publishers. Ewing, R., Schmid, T., Killingsworth, R., Zlot, A., \& Raudenbush, S. (2003). Relationship between urban sprawl and physical activity, obesity, and morbidity. American Journal of Health Promotion, 18(1), 47-57.

Ferreira, I., van der Horst, K., Wendel-Vos, W., Kremers, S., van Lenthe, F. J., \& Brug, J. (2007). Environmental correlates of physical activity in youth: A review and update. Obesity Reviews, 8(2), 129-154.

Finch, C. F., \& Donaldson, A. (2010). A sports setting matrix for understanding the implementation context for community sport. British Journal of Sports Medicine, 44, 973-978.

Frey, J. H., \& Eitzen, S. (1991). Sport and society. Annual Review of Sociology, 17, 503-522.

Garcia, A. W., Broda, M. A., Frenn, M., Coviak, C., Pender, N. J., \& Ronis, D. L. (1995). Gender and developmental differences in exercise beliefs among youth and prediction of their exercise behavior. Journal of School Health, 65(6), 213-219.

Glover, T. D. (2007). Ugly on the diamonds: An examination of white privilege in youth baseball. Leisure Sciences, 29, 195-208.

Gordon-Larsen, P., Nelson, M. C., Page, P., \& Popkin, B. M. (2006). Inequality in the built environment underlies key health disparities in physical activity and obesity. Pediatrics, 117(2), 417424.

Gottlieb, N. H., \& Chen, M. S. (1985). Sociocultural correlates of childhood sporting activities: The implications 
for heart health. Social Science \& Medicine, 21(5), 533-539.

Hansen, D. M., Larson, R. W., \& Dworkin, J. B. (2003). What adolescents learn in organized youth activities: A survey of self-reported developmental experiences. Journal of Research on Adolescence, 13, 25-55.

Hill, A. B. (1965). The environment and disease: Association or causation? Proceedings of the Royal Society of Medicine, 58, 295-300.

Hinkley, T., Crawford, D., Salmon, J., Okely, A. D., \& Hesketh, K. (2008). Preschool children and physical activity: A review of correlates. American Journal of Preventive Medicine, 34(5), 435-441.

Holt, N. L. (2008). Positive youth development through sport. London: Routledge.

Houlihan, B., \& Green, M. (2008). Comparative elite sport development. In B. Houlihan \& M. Green (Eds.), Comparative elite sport development: Systems, structures and public policy. Oxford, England: ButterworthHeinemann.

Khan, K. M., Thompson, A. M., Blair, S. N., Sallis, J. F., Powell, K. E., Bull, F. C., \& Bauman, A. E. (2012). Sport and exercise as contributors to the health of nations. The Lancet, 380(9836), 59-64.

Larson, R. W. (2000). Toward a psychology of positive youth development. American Psychologist, 55, 170-183.
Lowe Vandell, D., Shernoff, D. J., Pierce, K. M., M, B. D., Dadisman, K., \& Brown, B. B. (2005). Activities, engagement, and emotion in afterschool programs (and elsewhere). New Directions for Youth Development, 105, 121-129.

Mahoney, J. L., Larson, R. W., \& Eccles, J. S. (2005). Organized Activities as Contexts of Development: Extracurricular Activities, After-School, and Community Programs. Hillsdale, NJ: Lawrence Erlbaum Associates.

Mandic, S., Bengoechea, E. G., Stevens, E., de la Barra, S. L., \& Skidmore, P. (2012). Getting kids active by participating in sport and doing it more often: Focusing on what matters. International Journal of Behavioral Nutrition and Physical Activity, 9, 86-94.

Marsh, H. W., \& Kleitman, S. (2003). School athletic participation: Mostly gain with little pain. Journal of Sport and Exercise Psychology, 25(2), 205-228.

Massey, D. S. (1985). Ethnic residential segregation: A theoretical synthesis and empirical review. Sociology and Social Research, 69(3), 315-350.

Massey, D. S., \& Denton, N. A. (1988a). The dimensions of residential segregation. Social Forces, 67(2), 281315.

Massey, D. S., \& Denton, N. A. (1988b). Suburbanization and segregation in US metropolitan areas. American Journal of Sociology, 94(3), 592-626. 
Maxwell, H., \& Taylor, T. (2010). A culture of trust: Engaging Muslim women in community sport organizations.

European Sport Management Quarterly, 10(4), 465-483.

Michaud, P.A., Jeannin, A., \& Suris, J.C. (2006). Correlates of extracurricular sport participation among Swiss adolescents. European Journal of Pediatrics, 165(8), 546-555.

NCYS. (2015). About NCYS. Retrieved from http://www.ncys.org/about/about.p hp

Owen, N., Humpel, N., Leslie, E., Bauman, A., \& Sallis, J. F. (2004). Understanding environment influences on walking: Review and research agenda. American Journal of Preventive Medicine, 27(1), 67-76.

Owen, N., Leslie, E., Salmon, J., \& Fotheringham, M. J. (2000). Environmental determinants of physical activity and sedentary behavior. Exercise and Sport Sciences Review, 28(4), 153-158.

Peretti-Watel, P., Guagliard, V., Verger, P., Pruvost, J., Mignon, P., \& Obadia, Y. (2003). Sporting activity and drug use: Alcohol, cigarette and cannabis use among elite student athletes. Addiction, 98, 1249-1256.

Perkins, D. F., Jacobs, J. E., Barber, B. L., \& Eccles, J. S. (2004). Childhood and adolescent sports participation as predictors of participation in sports and physical fitness activities during young adulthood. Youth and Society, 35, 495-520.

Rosner, S., \& Crow, B. (2002). Institutional liability for hazing in interscholastic sports. Houston Law Review, 39(2), 276-300.

Roux, L., Pratt, M., Tengs, T., Yore, M., Yanagawa, T. L., Van Den Bos, J., .. . Buchner, D. M. (2008). Cost effectiveness of community-based physical activity interventions. Journal of Preventive Medicine, 35(6), 578-588.

Sabo, D., Miller, K. E., Melnick, M. J., Farrell, M. P., \& Barnes, G. M. (2005). High school athletic participation and adolescent suicide: A nationwide US study. International Review for the Sociology of Sport, 40(1), 523.

Sallis, J. F., Alcaraz, J. E., McKenzie, T. L., Hovell, M. F., Kolody, B., \& Nader, P. R. (1992). Parental behavior in relation to physical activity and fitness in 9-year-old children. American Journal of Diseases of Children, 146(11), 1383-1388.

Sallis, J. F., Hovell, M. F., Hofstetter, C. R., Elder, J. P., Hackley, M., Caspersen, C. J., \& Powell, K. E. (1990).

Distance between homes and exercise facilities related to frequency of exercise among San Diego residents. Public Health Report, 105, 179-185.

Sallis, J. F., Nader, P. R., Broyles, S. L., Berry, C. C., Elder, J. P., McKenzie, T. L., \& Nelson, J. A. (1993). 
Correlates of physical activity at home in Mexican-American and Anglo-American preschool children. Health Psychology, 12(5), 390-398. Sallis, J. F., Prochaska, J. J., \& Taylor, W. C. (2000). A review of correlates of physical activity of children and adolescents. Medicine and Science in Sports and Exercise, 32, 963-975. Schulenkorf, N., \& Edwards, D. (2012). Maximizing positive social impacts: Strategies for sustaining and leveraging the benefits of intercommunity sport events in divided societies. Journal of Sport Management, 26, 379-390.

Seifried, C. (2011). Sport facilities as a broadcast studio for human extensibility? Geographic information system-based diagrams of a high- and low-identified sport fan. Journal of Sport Management, 25, 515-530.

Small, E. (2002). Kids and sports: Everything you and your child need to know about sports, physical activity, nutrition, and good health a doctor's guide for parents and coaches. New York, NY: Newmarket Press. Stalsberg, R., \& Pedersen, A. V. (2010). Effects of socioeconomic status on the physical activity in adolescents: A systematic review of the evidence. Scandinavian Journal of Medicine and Science in Sports, 20, 368-383.

Strong, W. B., Malina, R. M., Blimkie, C. J., Daniels, S. R., Dishman, R. K., Gutin, B., Hergenroeder, A. C., Must, A., Nixon, P. A., Pivarnik, J. M.,
Rowland, T., Trost, S., \& Trudeau, F. (2005). Evidence based physical activity for school-age youth. The Journal of pediatrics, 146(6), 732-737.

The Aspen Institute. (2015). Facts: Sports Activity and Children. Retrieved from http://www.aspenprojectplay.org/th e-facts

van der Horst, K., Paw, M. J. C. A., Twisk, J. W. R., \& van Mechelen, W. (2007). A brief review on correlates of physical activity and sedentariness in youth. Medicine and Science in Sports and Exercise, 39(8), 1241-1250.

Welk, G. J., Wood, K., \& Morss, G. (2003). Parental influences on physical activity in children: An exploration of potential mechanisms. Pediatric Exercise Science, 15, 19-33.

Wicker, P., Hallmann, K., \& Breuer, C. (2013). Analyzing the impact of sport infrastructure on sport participation using geo-coded data: Evidence from multi-level models. Sport Management Review, 16, 54-67.

Xiong, H. (2007). The evolution of urban society and social changes in sports participation at the grassroots in China. International Review for the Sociology of Sport, 42(4), 441-471.

Yang, X., Telama, R., \& Laakso, L. (1996). Physical activity, socioeconomic status and education as predictors of physical activity and sport among children and youths: A 12 year follow up study. International Review of the Sociology of Sport, 31, 273-294. 
Table 1

\section{Tables}

Number of Participants by Facilities and Sport

\begin{tabular}{|c|c|c|c|c|c|c|c|c|c|c|}
\hline \multirow{2}{*}{ Facility } & \multicolumn{8}{|c|}{ Sport } & \multirow{2}{*}{$\begin{array}{c}\text { Total } \\
\text { participants by } \\
\text { facility }\end{array}$} & \multirow{2}{*}{$\begin{array}{l}\text { \# sports } \\
\text { by facility }\end{array}$} \\
\hline & $T F$ & $F F$ & $V B$ & $C L$ & $S C$ & $B K$ & $\begin{array}{c}B B / T \\
B\end{array}$ & $S B$ & & \\
\hline 1 & 24 & 0 & 0 & 23 & 0 & 0 & 0 & 0 & 47 & 2 \\
\hline 2 & 0 & 0 & 0 & 0 & 0 & 112 & 0 & 0 & 112 & 1 \\
\hline 3 & 18 & 0 & 0 & 0 & 0 & 0 & 0 & 0 & 18 & 1 \\
\hline 4 & 0 & 104 & 0 & 0 & 135 & 0 & 122 & 47 & 408 & 4 \\
\hline 5 & 0 & 222 & 0 & 0 & 17 & 0 & 239 & 0 & 478 & 3 \\
\hline 6 & 0 & 0 & 0 & 0 & 0 & 60 & 0 & 0 & 60 & 1 \\
\hline 7 & 50 & 27 & 0 & 30 & 9 & 58 & 0 & 0 & 174 & 5 \\
\hline 8 & 0 & 87 & 0 & 0 & 110 & 0 & 125 & 0 & 322 & 3 \\
\hline 9 & 0 & 60 & 0 & 0 & 62 & 0 & 0 & 0 & 122 & 2 \\
\hline 10 & 23 & 331 & 0 & 20 & 535 & 0 & 380 & 237 & 1,526 & 6 \\
\hline 11 & 71 & 0 & 0 & 39 & 120 & 0 & 0 & 0 & 230 & 3 \\
\hline 12 & 24 & 0 & 249 & 13 & 0 & 89 & 0 & 0 & 375 & 4 \\
\hline 13 & 0 & 127 & 0 & 0 & 125 & 0 & 133 & 0 & 385 & 3 \\
\hline 14 & 85 & 111 & 0 & 47 & 149 & 0 & 136 & 29 & 557 & 6 \\
\hline 15 & 0 & 114 & 0 & 0 & 69 & 89 & 0 & 0 & 272 & 3 \\
\hline 16 & 23 & 0 & 0 & 0 & 0 & 0 & 0 & 0 & 23 & 1 \\
\hline 17 & 0 & 0 & 0 & 0 & 0 & 0 & 0 & 57 & 57 & 1 \\
\hline 18 & 0 & 69 & 0 & 0 & 0 & 185 & 84 & 0 & 338 & 3 \\
\hline 19 & 55 & 42 & 0 & 8 & 43 & 0 & 0 & 0 & 148 & 4 \\
\hline $\begin{array}{c}\text { Total } \\
\text { participants } \\
\text { by sport }\end{array}$ & 373 & 1,294 & 249 & 180 & 1,374 & 593 & 1,219 & 370 & 5,652 & \\
\hline $\begin{array}{l}\text { \# facilities } \\
\text { by sport }\end{array}$ & 9 & 11 & 1 & 6 & 11 & 6 & 7 & 4 & & \\
\hline $\begin{array}{l}\text { \# teams by } \\
\text { sport }\end{array}$ & 16 & 90 & 21 & 14 & 123 & 61 & 81 & 37 & 443 & \\
\hline $\begin{array}{l}\text { Avg dist } \\
\text { (miles) by } \\
\text { sport }\end{array}$ & 4.8 & 4.3 & 6.8 & 4.6 & 5.1 & 5.0 & 4.4 & 5.9 & & \\
\hline Min dist & .14 & .12 & .69 & .16 & .12 & .16 & .14 & .18 & & \\
\hline Max dist & 26.7 & 22.1 & 24.3 & 19.9 & 27.0 & 32.6 & 25.5 & 31.0 & & \\
\hline
\end{tabular}

Notes. $\mathrm{TF}=$ Tackle Football, $\mathrm{FF}=$ Flag Football, $\mathrm{VB}=$ Volleyball, $\mathrm{CL}=$ Cheerleading, $\mathrm{SC}=$ Soccer, $\mathrm{BK}=$ Basketball, $\mathrm{BB} / \mathrm{TB}=$ Baseball $/ \mathrm{T}$-ball, $\mathrm{SB}=$ Softball

Journal of Amateur Sport Special Issue: Political Economy ～Kim et al., 2016 
Table 2

ANOV A: Mean Distance Traveled to Assigned Facilities by Sport

\begin{tabular}{|c|c|c|c|c|c|}
\hline Source & $d f$ & $S S$ & $M S$ & $F$ & $p$ \\
\hline $\begin{array}{l}\text { Between } \\
\text { groups }\end{array}$ & 7 & 2157.44 & 308.21 & 25.61 & .00 \\
\hline Within groups & 5,644 & 67917.87 & 12.03 & & \\
\hline Total & 5,651 & 70075.31 & & & \\
\hline
\end{tabular}

Table 3

Racial Profiles of Blocks of Participants by Sport Types

\begin{tabular}{lllll} 
Sport & White (\%) & $\begin{array}{c}\text { African-American } \\
(\%)\end{array}$ & Difference $(\%)$ & Total(\%) \\
\hline Tackle Football & 52.7 & 41.4 & 11.3 & 94.1 \\
Flag Football & 68.7 & 25.1 & 43.6 & 93.8 \\
Volleyball & 70.9 & 22.9 & 48 & 93.8 \\
Cheerleading & 47.9 & 47.0 & 0.9 & 94.9 \\
Soccer & 70.0 & 23.9 & 46.1 & 93.9 \\
Basketball & 61.4 & 32.7 & 28.7 & 94.1 \\
Baseball & 76.2 & 17.3 & 58.9 & 93.5 \\
Softball & 73.6 & 20.1 & 53.5 & 93.7 \\
Mean & 65.2 & 28.8 & 36.4 & \\
\hline
\end{tabular}

Table 4

Median Income of Block of Participants by Sport Types

\begin{tabular}{ll}
\hline Sport & Median Income \\
\hline Tackle Football & 48,866 \\
Flag Football & 71,713 \\
Volleyball & 70,691 \\
Cheerleading & 47,465 \\
Soccer & 71,772 \\
Basketball & 61,146 \\
Baseball & 78,323 \\
Softball & 77,125 \\
Mean & 65,888
\end{tabular}

Journal of Amateur Sport Special Issue: Political Economy $\quad$ Kim et al., 2016 
Table 5

Multivariate Regression: Travel Distance to Participate in YSP and Percentage of White Residents from Home Neighborbood

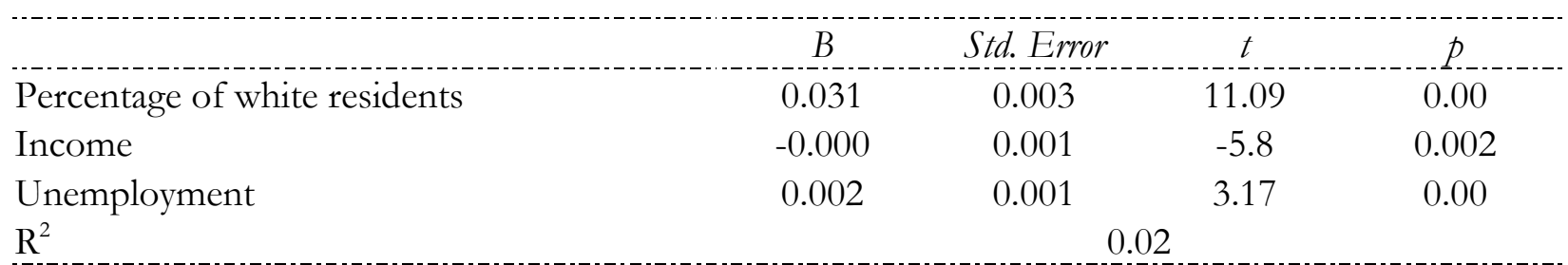




\section{Figures}

Figure 1

A Theoretical Sketch of the Complex Relations of Neighborhood, Sport Participation, and Community-Building

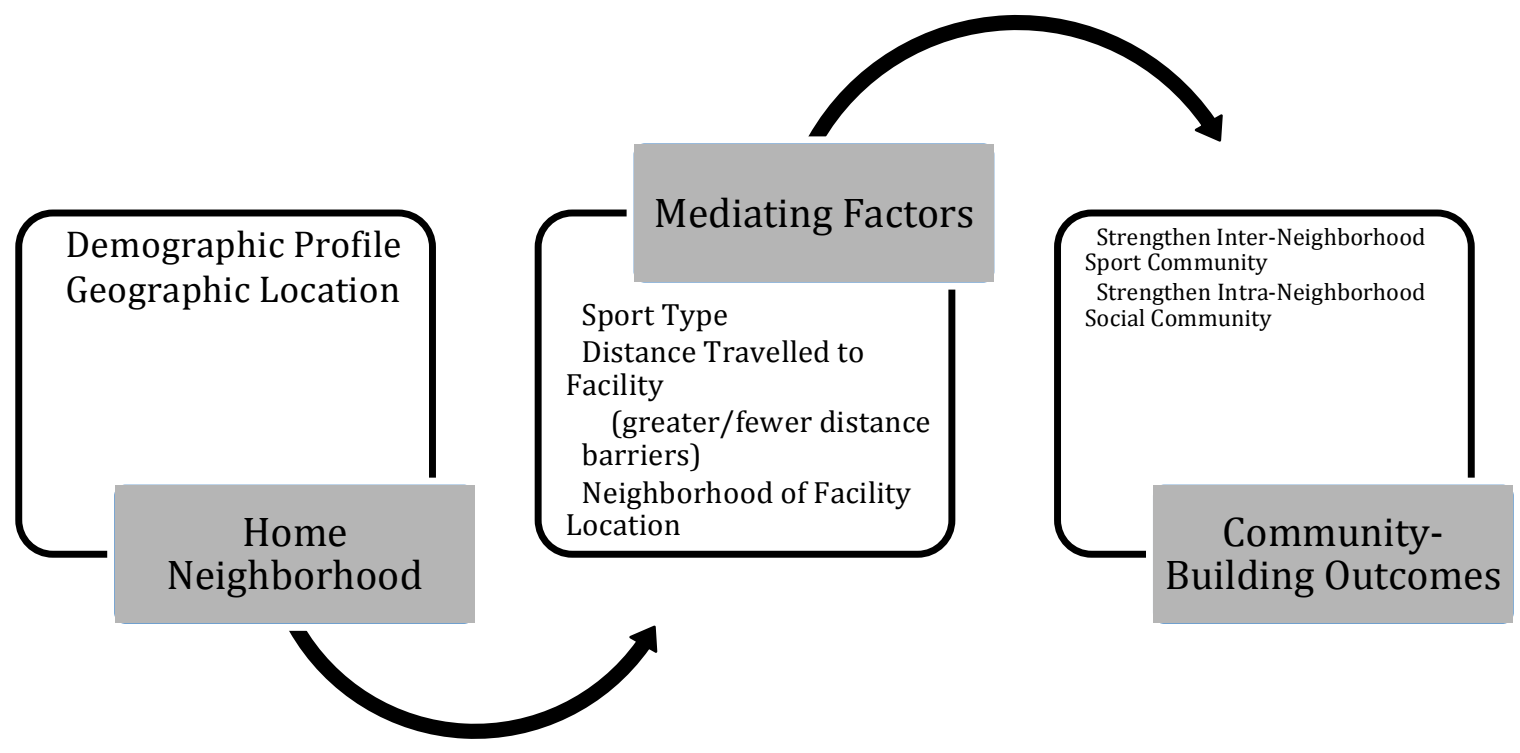


Figure 2

Visualization of Travel Distance of Each Facility and $r$ Neighborhood Race Demographics

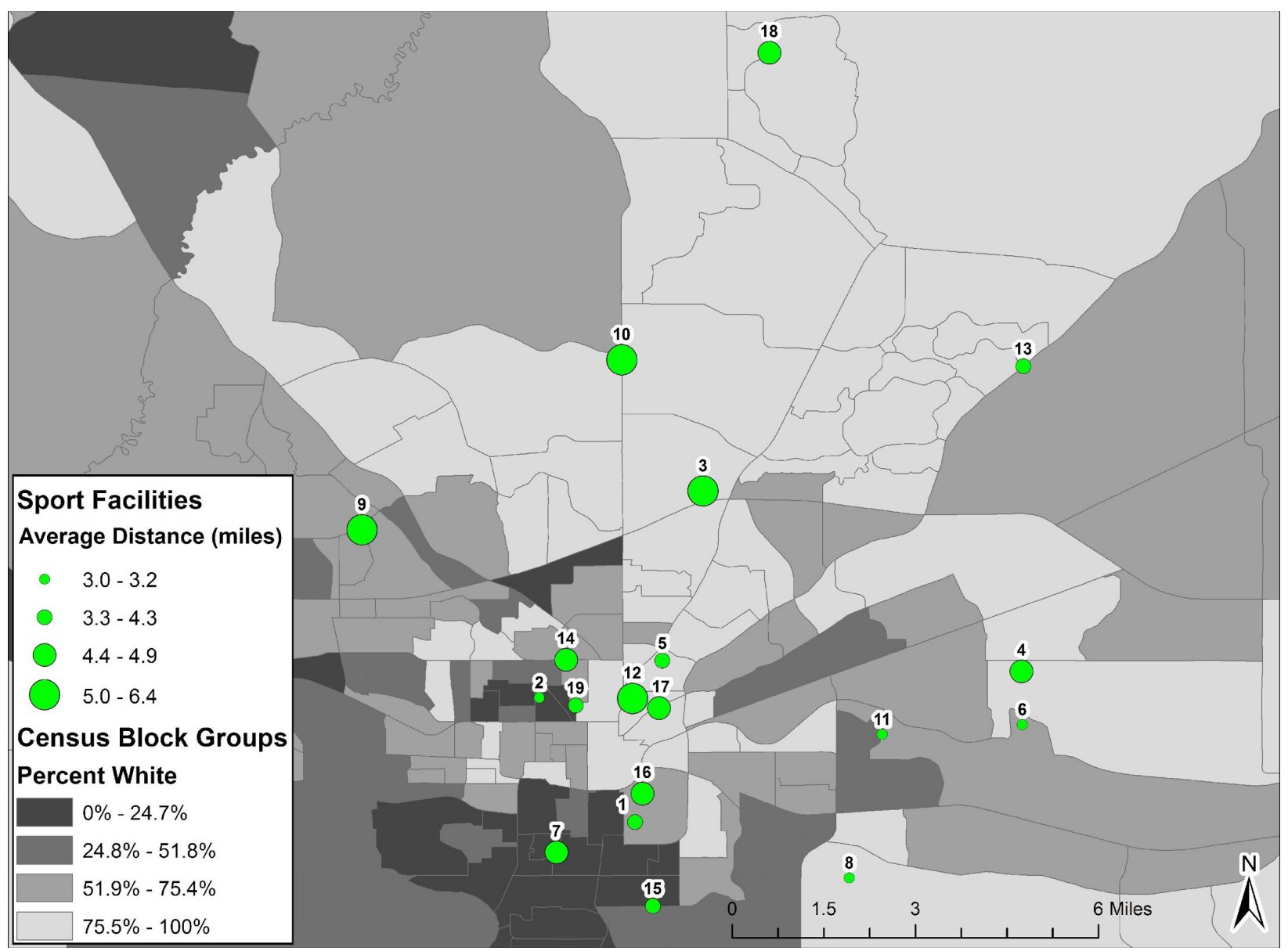


Figure 3

Aggregated Cluster Analysis Visualization of Distance Traveled to YSP Facilities in Relation to Neighborbood Race Demographics

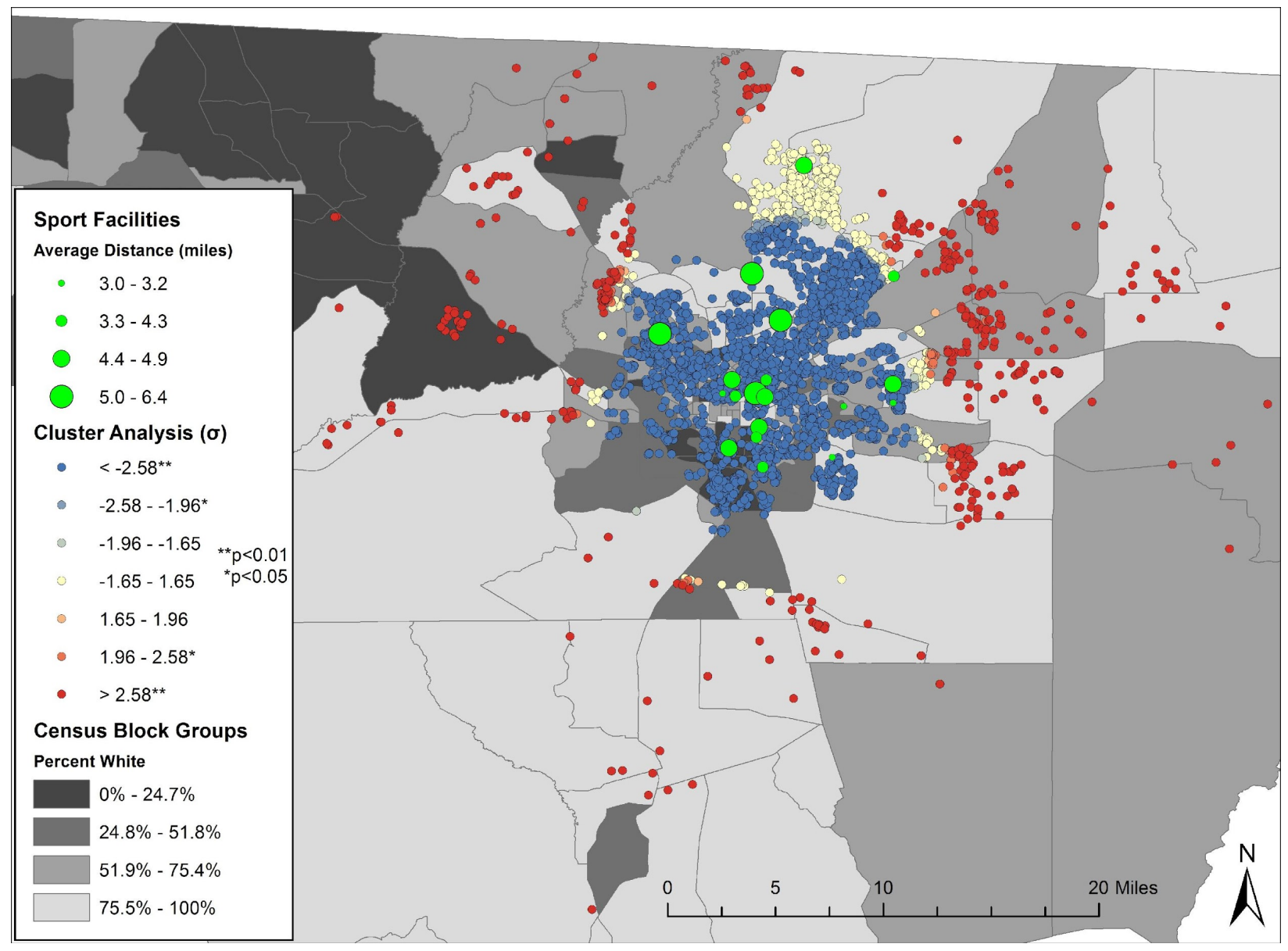


Figure 4

Cluster Analysis Visualization of Distance Travelled for Tackle Football and Travel Distance and Neighborbood Race Demographics

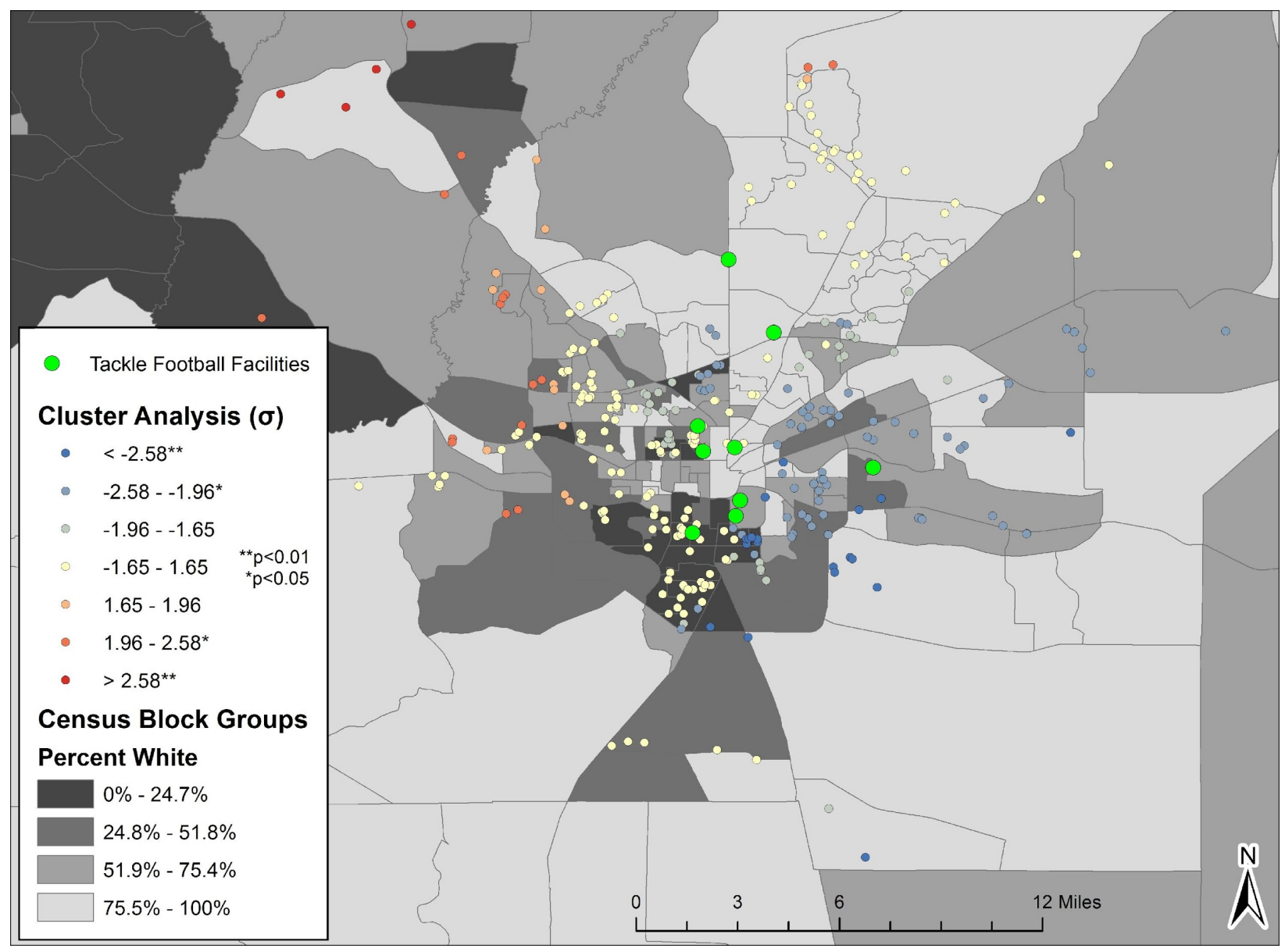


Figure 5

Cluster Analysis Visualization of Distance Travelled for Flag Football and Travel Distance and Neighborbood Race Demographics

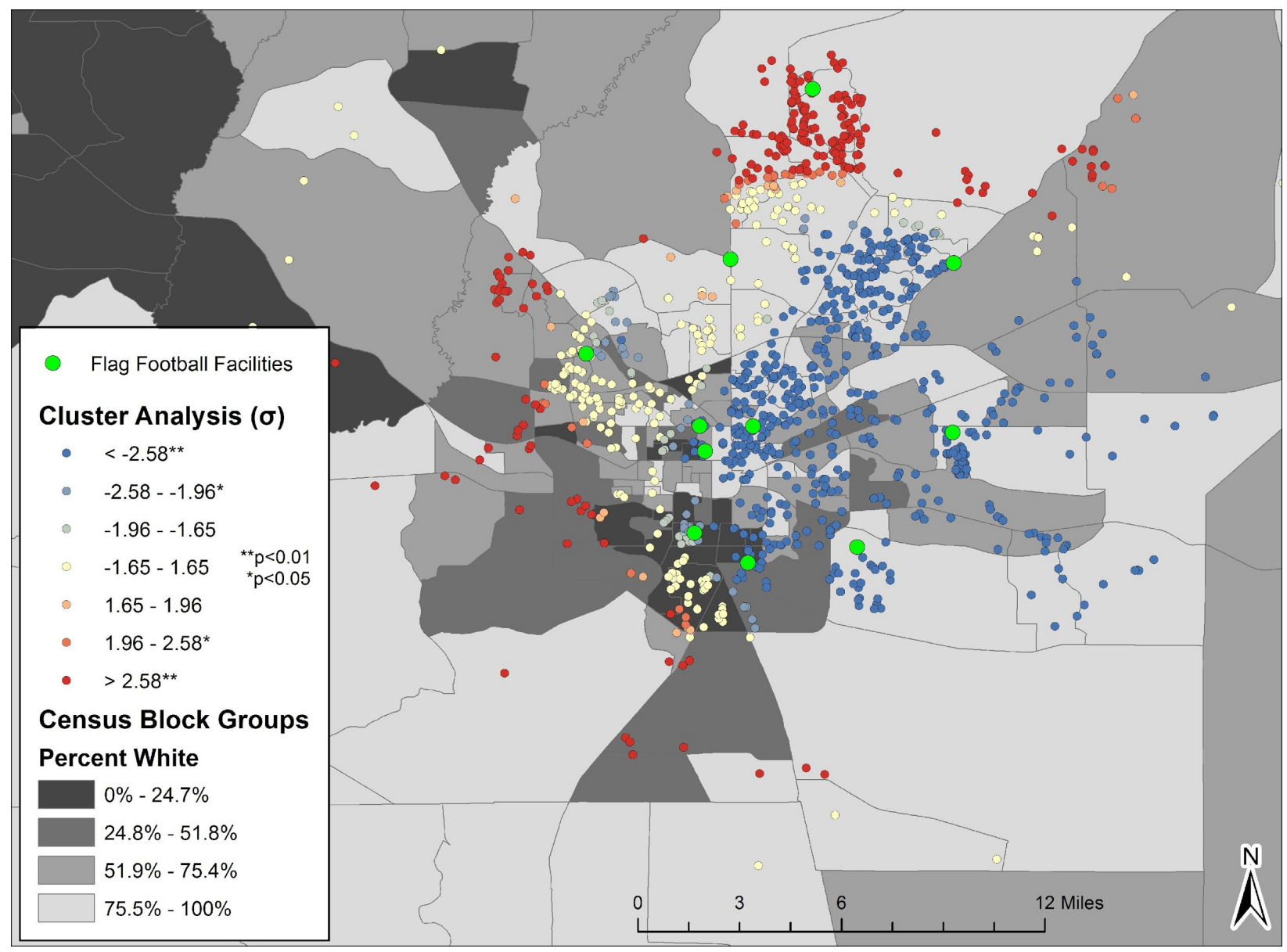


Figure 6

Cluster Analysis Visualization of Distance Travelled for Volleyball and Travel Distance and Neighborbood Race Demographics

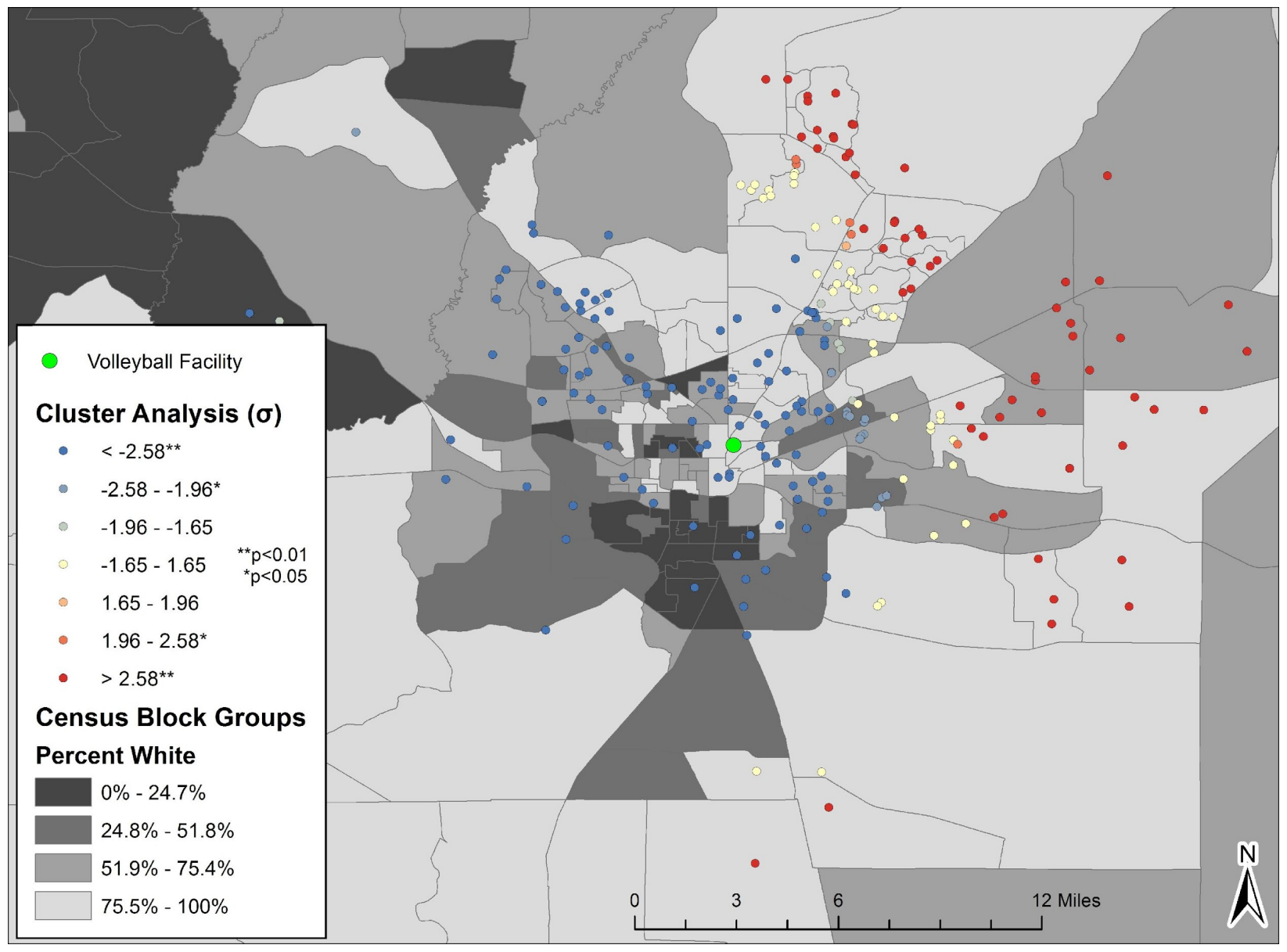


Figure 7

Cluster Analysis Visualization of Distance Travelled for Cheerleading and Travel Distance and Neighborbood Race Demographics

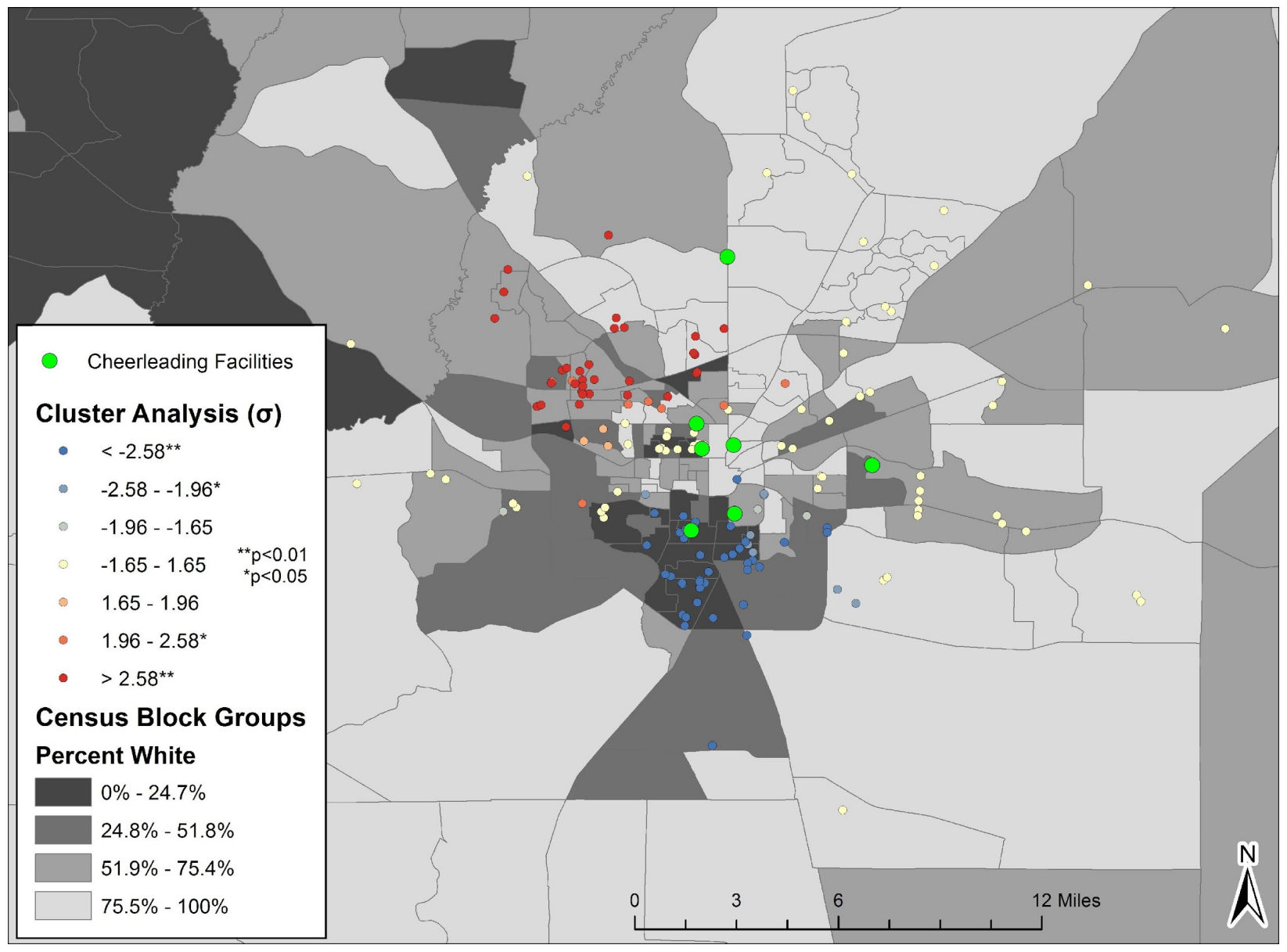


Figure 8

Cluster Analysis Visualization of Distance Travelled for Softball and Travel Distance and Neighborbood Race Demographics

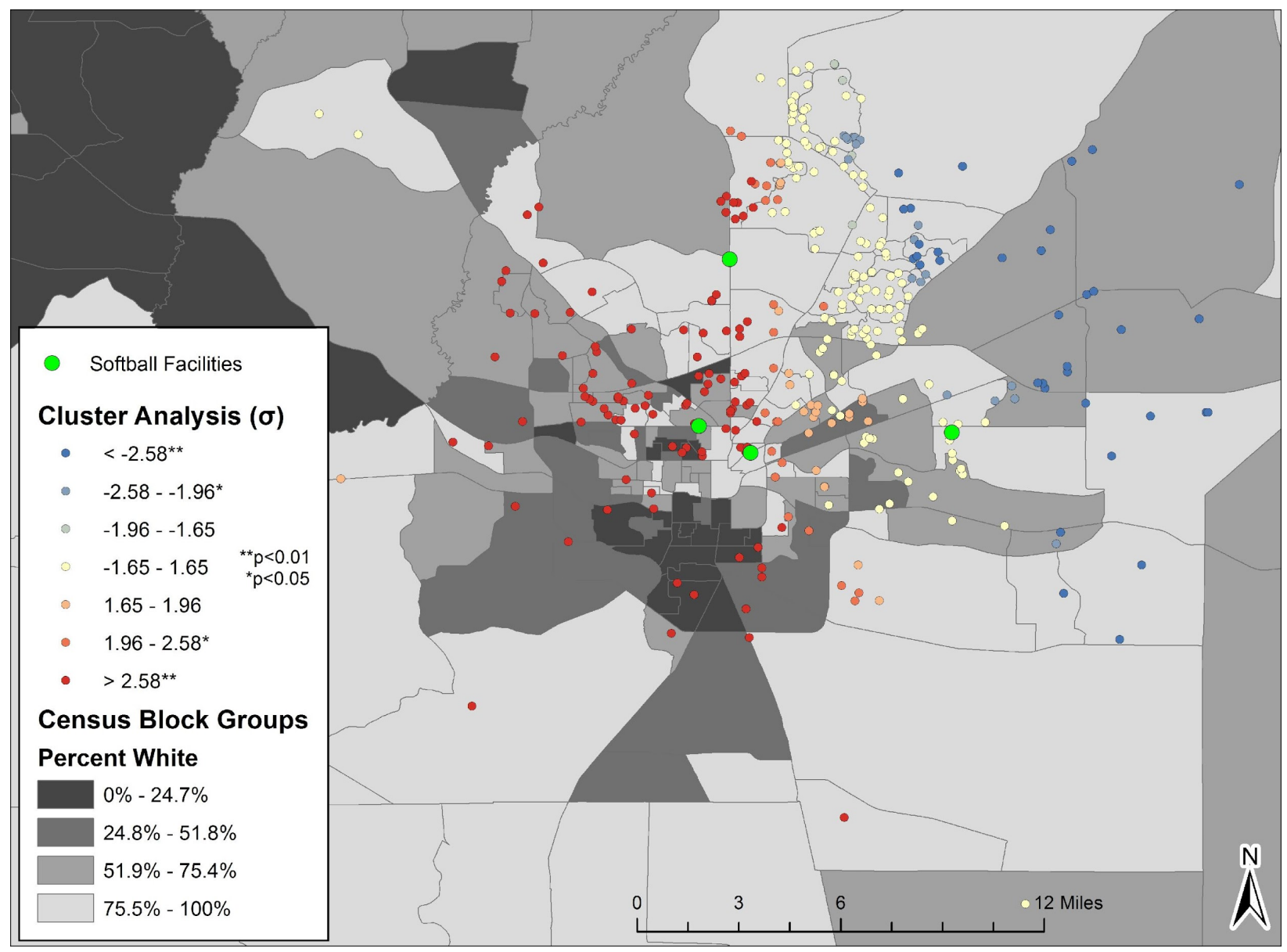


Figure 9

Cluster Analysis Visualization of Distance Travelled for Baseball/T-ball and Travel Distance and Neighborbood Race Demographics

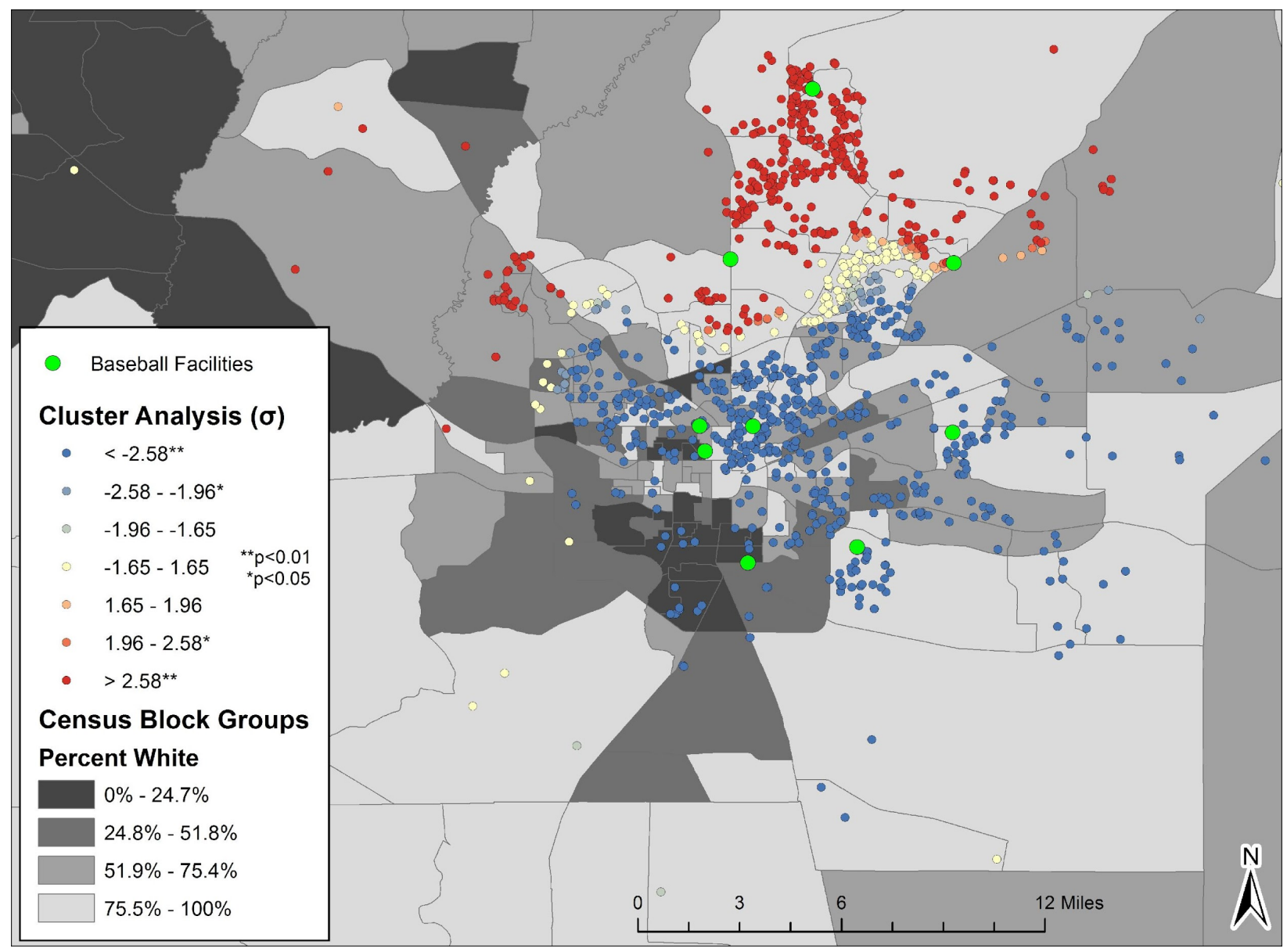


Figure 10

Cluster Analysis Visualization of Distance Travelled for Soccer and Travel Distance and Neighborbood Race Demographics

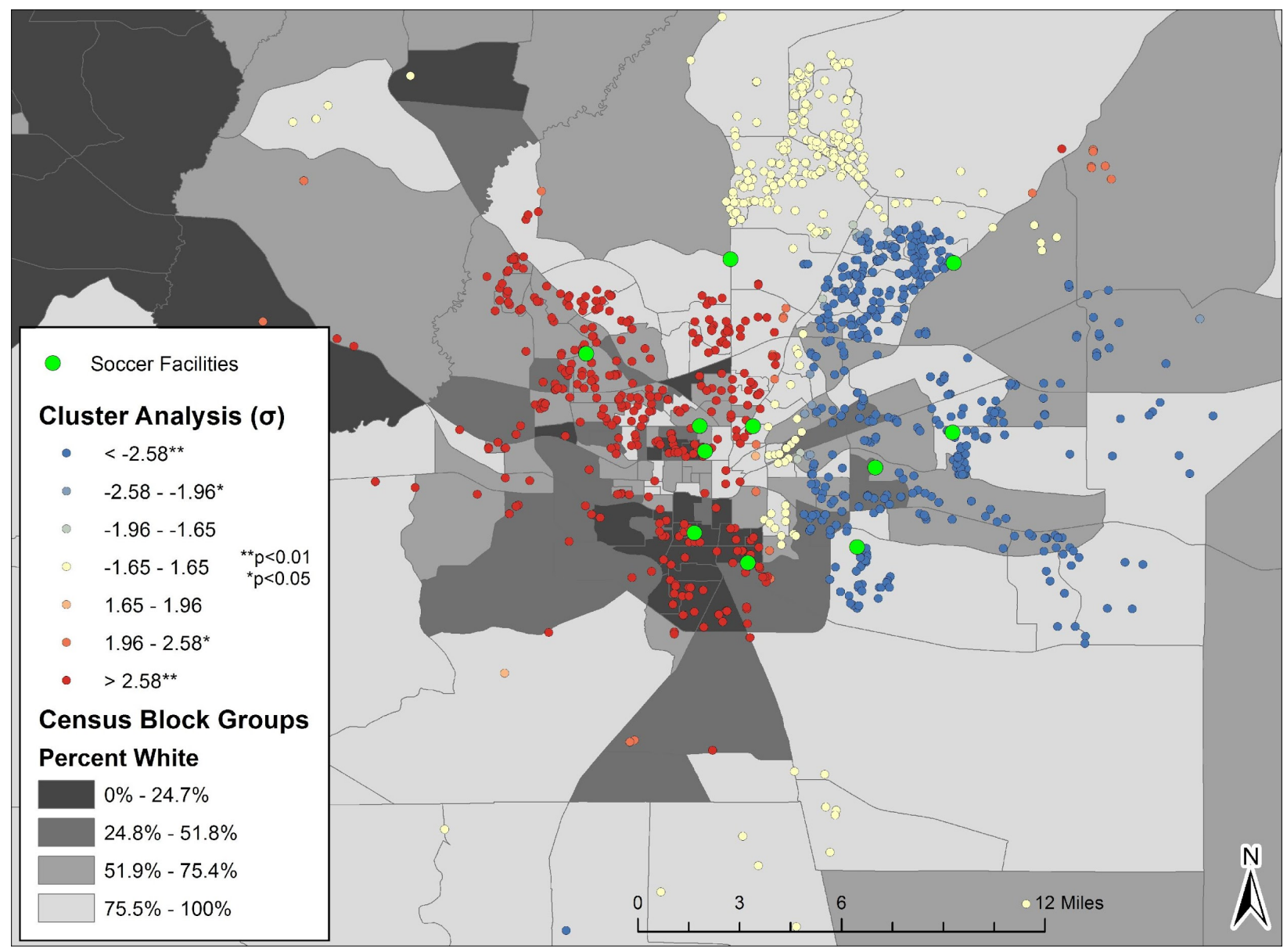


Figure 11

Cluster Analysis Visualization of Distance Travelled for Basketball and Travel Distance and Neighborhood Race Demographics

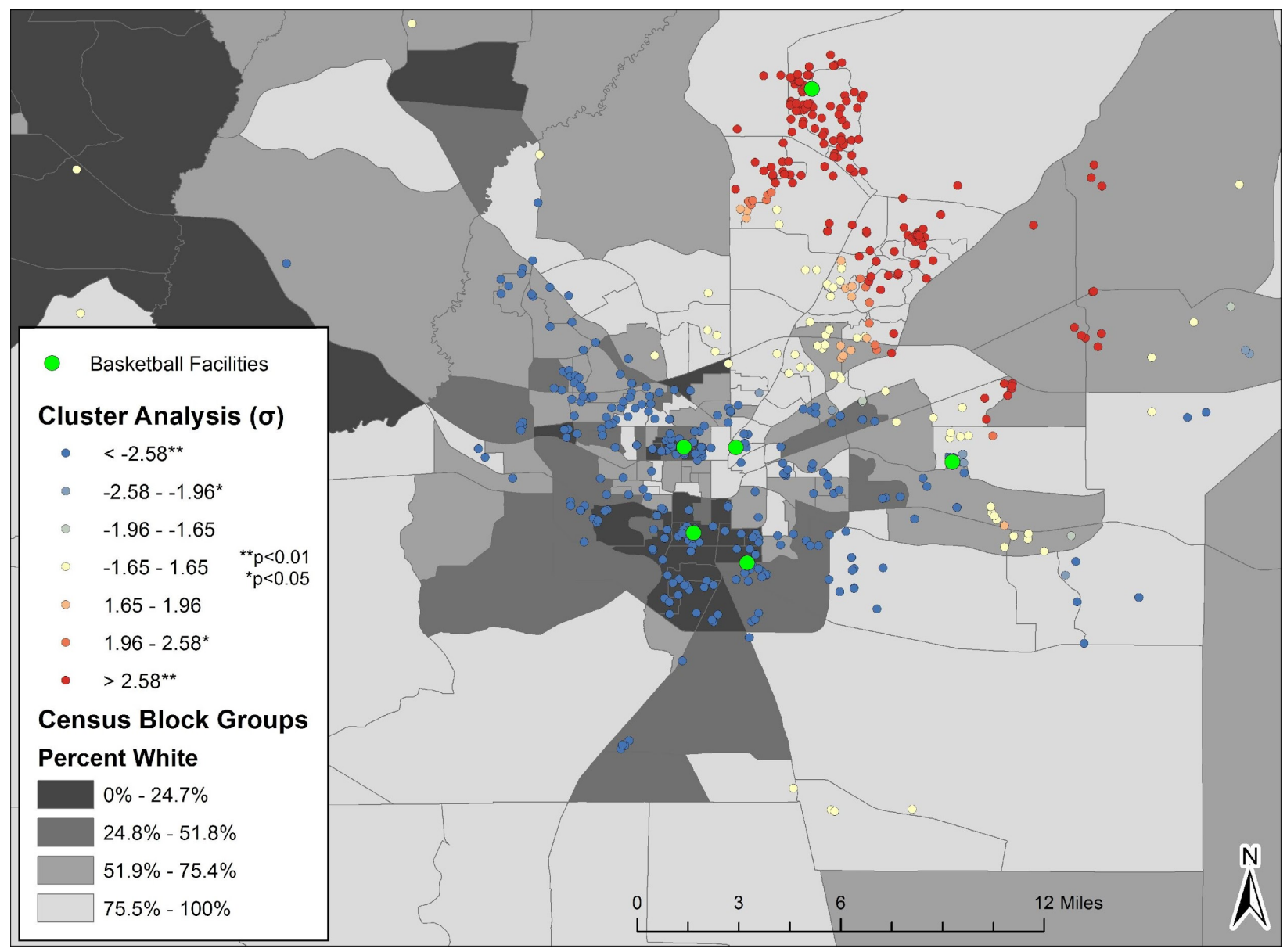

